\title{
Análisis Icónico e Iconográfico de un Procedimiento Dental Mapuche Fotografiado por Gustavo Milet
}

\author{
Iconic and Iconographic Analysis of a Mapuche \\ Dental Procedure Photographed by Gustavo Milet
}

\author{
Alonso Azócar"; Mario Cantín ${ }^{* *, * * *}$; Héctor Silva Mella ${ }^{* * *}$; Tania Flores Lillo*; \\ Nicolás Ernesto Ottone ${ }^{* *}$ \& Ramón Fuentes ${ }^{* *}$
}

\begin{abstract}
AZÓCAR, A.; CANTÍN, M.; SILVA, M. H.; FLORES, L. T.; OTTONE, N. E. \& FUENTES, R. Análisis icónico e iconográfico de un procedimiento dental mapuche fotografiado por Gustavo Milet. Int. J. Odontostomat., 9(1):97-100, 2015.

RESUMEN: La vital relación del mapuche con la tierra, no sólo abarca el ámbito de subsistencia material, sino que también encuentra allí su expresión espiritual. El presente estudio otorga una sutil mirada al complejo sistema médicoreligioso del pueblo mapuche, sus conceptos de salud, costumbres y acciones orientadas a resolver necesidades cotidianas de carácter médico- odontológico, las cuales son reveladas a través de un completo análisis icónico e iconográfico de una fotografía de Gustavo Milet.
\end{abstract}

PALABRAS CLAVE: extracción de dientes, dentista, Mapuche, fotografía.

\section{INTRODUCCIÓN}

Los mapuches, autodenominados hombres de la tierra, nacen de una lucha desatada entre el océano y la cordillera, los dos elementos centrales que modelan su territorio y su cultura. La vital relación del mapuche con la tierra, no sólo abarca el ámbito de la subsistencia material, sino que también encuentra allí su expresión espiritual, su cosmovisión, la forma en que representa al mundo y su interacción con las fuerzas sobrenaturales. Esta vinculación con su territorio explica su voluntad de independencia, que no en vano mantuvieron durante tres siglos y medio, luchando sin tregua por la libertad (Memoria chilena, 2004). En la actualidad constituyen el grupo indígena más numeroso de Chile $(87,3 \%)$, alcanzando alrededor de un millón de personas en las zonas central y sur de Chile. EI $23,5 \%$ de la población de la Región de La Araucanía, mayor de 14 años, se declara mapuche (Instituto Nacional de Estadísticas, 2005).

Zapater (1978) señala que los araucanos primitivos carecían de un lenguaje escrito; razón por la cual la mayor parte de lo que conocemos de ellos, sus costumbres en general, su medicina y sus creencias, son producto de crónicas escritas durante la dominación española por historiadores que en su mayoría fueron eclesiásticos o militares. La sociedad mapuche era patriarcal y su núcleo básico lo constituía la familia, que estaba formada por el hombre, jefe del hogar, una o varias mujeres y los hijos. El hombre sencillo tenía dos mujeres. Otros, socialmente mejor situados, como caciques, hijos de caciques y machis, tenían cuatro o más mujeres y en ocasiones practicaban la poligamia sororal.

La medicina Mapuche, al igual que otras medicinas primitivas, estaba basada en el concepto mágico de enfermedad. Las patologías o la muerte no tenían un origen orgánico o natural, sino que eran consecuencia de la acción de fuerzas maléficas sobre las personas. El agente de salud, él o la machi, mezcla de médico, sacerdote y hechicero, era seleccionado entre sus semejantes por alguna característica particular (algún defecto físico, haber sobrevivido a un ac-

\footnotetext{
Departamento de Lenguas, Literatura y Comunicación, Facultad de Educación, Ciencias Sociales y Humanidades, Universidad de La Frontera, Temuco, Chile.

* Departamento Odontología Integral Adulto, Facultad de Odontología, Universidad de La Frontera, Temuco, Chile.

*** Centro de Investigación en Ciencias Biomédicas, Universidad Autónoma de Chile, Temuco, Chile.

**** Departamento de Ciencias Básicas, Facultad de Medicina, Universidad de La Frontera, Temuco, Chile.
} 
cidente o una enfermedad grave). La machi recibía una intensa preparación antes de ejercer su rol en la comunidad, debiendo conocer sobre las múltiples propiedades de las hierbas y su empleo. Una de las prácticas más interesantes en su sistema médico-religioso era el machitún, que consistía en la invocación, por parte de la machi, de los antepasados del mundo espiritual, que manejan el arte de diagnosticar enfermedades y todo tipo de males, y de este modo, asisten a la machi en sus diagnosis y tratamientos.

Otras de sus prácticas medicinales se basaban en el conocimiento de las hierbas o herbolaria, practicando el empirismo; además de algunas cirugías elementales (Zúñiga Rocha, 2001). Según Plath (1981), todas las actividades de salud estaban condicionadas por la actitud de la población hacia la enfermedad, manteniendo conceptos propios sobre la salud y la curación de enfermedades. Tales concepciones aseguraban, a quienes las compartían, una percepción de seguridad muy fuerte. Sus conceptos parecían inamovibles y se resistían a ideas extrañas, cuando estas amenazaban quebrantar las suyas. Entre sus conceptos odontológicos básicos se encontraba el dolor dentario, el cual se definía como "dolor de muelas", correspondiéndose a cualquier dolor en la zona de dientes o molares, abarcando el grupo de las pulpitis, neuralgias, abscesos e inflamaciones. También establecen los "males de dientes", cuya etiología es descrita del siguiente modo: "las muelas duelen por estar picadas, por tomar mate y salir al aire o por tomar algo caliente y descuidarse con las corrientes" (Plath). Por su parte, en relación a la curación de ciertas afecciones, ante el padecimiento de cefaleas, "aire", odontalgias e inflamaciones de la cara, lo primero que se prescribía era amarrársela.

Para las odontalgias o "dolores de muelas", se cubrían los costados de la cara con un pañuelo, el que se sujetaba con un nudo en la parte alta de la cabeza. En caso de que el dolor no cediera, se practicaba la extracción dental de "dientes picados". Para dicha intervención se describía que "el sacamuelas y su cliente se ponían junto a un árbol de mediano grosor" (Plath). Posteriormente, "... el paciente se arrodillaba a un lado del árbol y se asía con las manos al tronco; el operador se ponía al otro lado y apoyaba sobre el árbol las dos ramas abiertas de unas tenazas de madera de $80 \mathrm{~cm}$. de largo, terminadas en extremo llano. Cuando la pieza dentaria estaba sujeta fuertemente, el operador hacía palanca con el tronco mientras que el operado se enderezaba, y, de este modo, molares, incisivos y caninos salían de un solo golpe" (Plath). Dicho procedimiento odontológico, de extrac- ción de una pieza dental, fue fotografiado por Gustavo Milet, retratista neto nacido en Valparaíso, Chile, que alcanza notoriedad con sus fotos de estudio a sujetos mapuches, "Araucanos", los que se constituyen en actores de esta fotografía, cuyo análisis detallado se presenta en la sección material y método (Fig. 1).

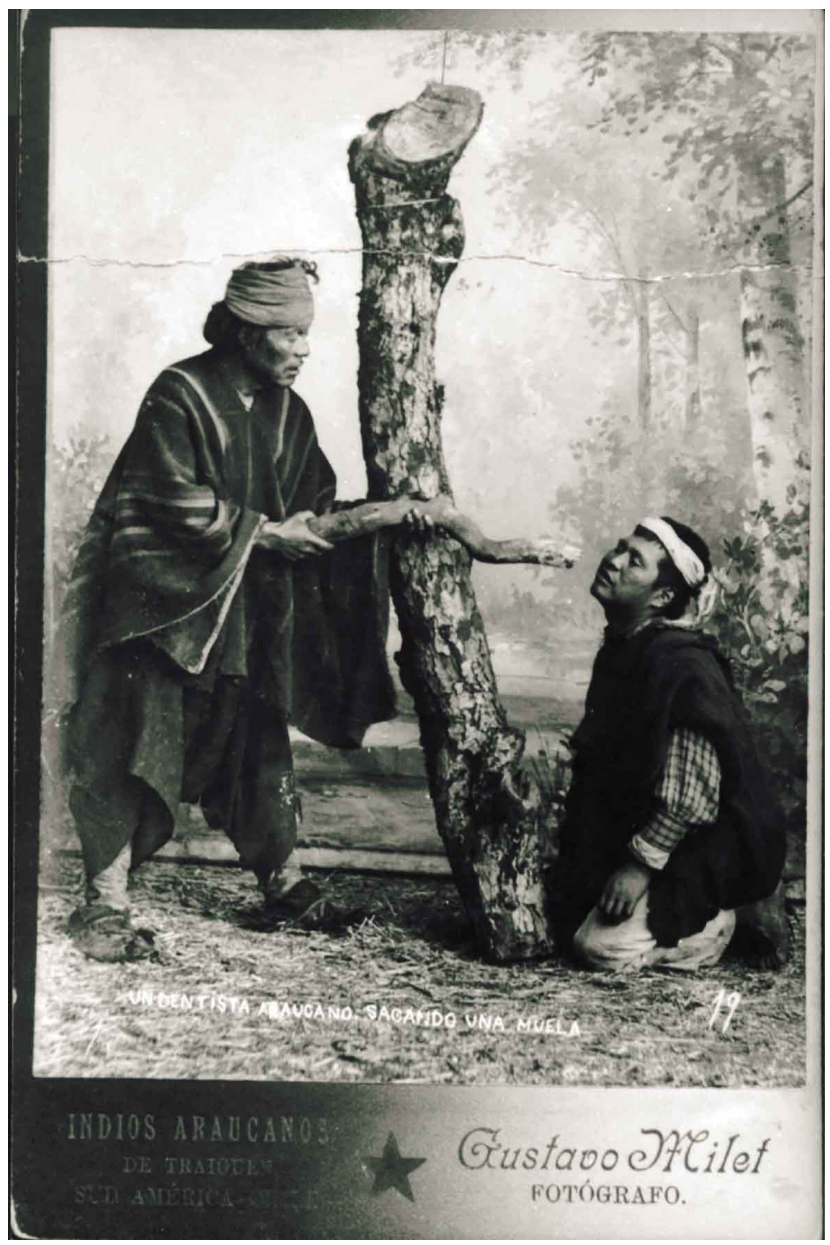

Fig. 1. "Un dentista araucano sacando una muela" (sic) (Original de G. Milet, tomado de Azócar, 2005). Análisis icónico.

\section{MATERIAL Y MÉTODO}

Análisis icónico. Plano entero, en formato vertical, en donde pueden verse dos varones adultos interactuando. El espacio físico está constituido por un telón pintado con abedules, plantas y algunos peldaños. Delante de él se extiende el suelo cubierto de pasto seco. En el centro de la fotografía hay un tronco, uno de cuyos extremos está afirmado en el suelo, mientras el otro lleva amarrada una delgada cuerda que lo sostiene de algo que está fuera del encuadre. La fotografía está montada en formato Cabinet. En la parte inferior de la fotogra- 
fía puede leerse: "Un dentista araucano sacando una muela" (sic). Frase que identifica el significado de una escena que, de otra manera, sería muy difícil de interpretar por parte de quien no conozca esta práctica. La posición de la cámara es lateral y el lente usado es de $230 \mathrm{~mm}$ o bien un teleobjetivo corto. Se ha usado una pequeña abertura de diafragma lo que permite una total profundidad de campo, que deja enfocados tanto a la figura (los dos hombres y el tronco) como el fondo (el telón). La iluminación es diurna, amplia, suave y cae desde la derecha de la escena en un ángulo de, aproximadamente, $45^{\circ}$. La cámara está ubicada a la altura de los hombros de la persona que se encuentra de pie. El acontecimiento representado corresponde a la atención de un dentista. El espacio representado es un ambiente exterior, para lo cual se utiliza un telón con un paisaje pintado. La película usada es de baja sensibilidad, de grano fino, lo que permite un buen contraste y riqueza de definición en los detalles. La velocidad de obturación es lo suficientemente rápida para detener todo movimiento. El hombre de la izquierda, el dentista, está de pie, vestido con una chiripa amplia, de color gris oscuro, un poncho gris oscuro con franjas delgadas blancas y grises (de distinto tono) y camisa blanca. Un pañuelo rodea su cabeza y calza ojotas de cuero y calcetines o medias. El varón de la derecha es más joven y está de rodillas frente al dentista. Es el paciente. Viste pantalones blancos, camisa a cuadros y poncho negro. Un pañuelo en forma de faja rodea su cabeza. Está descalzo, tiene la cabeza echada un poco hacia atrás, presentando su cara al dentista. Entre ambos hay un tronco en posición vertical. El hombre de la izquierda, sostiene un pequeño tronco de árbol con ambas manos, uno de cuyos extremos casi toca la cara del paciente, cuyo rostro es el principal punto de atracción focal de esta composición, realizada a partir de la interacción de los personajes. Además de la frase escrita dentro de la fotografía, hay un número 19 en el extremo inferior derecho. Fuera del encuadre, en el extremo inferior izquierdo, en el cartón coloreado de gris, en un degradé de oscuro a claro, está impreso con letras doradas: Indios Araucanos de Traiguén, Sudamérica, Chile. En el extremo inferior derecho de esta porción de la imagen, está impreso el nombre del autor de la fotografía: Gustavo Milet, fotógrafo. Separa ambos textos lingüísticos una estrella de cinco puntas del mismo color.

Análisis iconográfico. Esta imagen, más que como un texto visual, debe considerarse como un texto mixto, en el sentido planteado por Metz (1970). Es decir, hay una relación de dependencia entre el texto visual y el lingüístico que señala que se trata de un "dentista araucano sacando una muela”. Además, inmediata- mente, otro texto lingüístico aclara donde habitan estos "indios araucanos". Anclado el significado de manera tan precisa, sólo queda creer lo escrito por el autor e intentar explicarse el procedimiento de extracción, o dudar de lo afirmado por el autor, a partir de prejuicios prevalentes, reforzados por los estereotipos dominantes de la época. Dado que se trata de hacer una lectura iconográfica que busque interpretar la visión del autor en relación al pueblo mapuche, es necesario señalar que en este texto el significante fundamental es la definición de la acción y sus ejecutantes. Milet coloca a la medicina curativa "araucana" en un alto nivel, señalando que la sociedad mapuche de finales del siglo pasado contaba con profesionales, en el área de la salud, que cumplían labores similares a los de la sociedad global. Contaban con dentistas. Las relaciones entre los dos participantes en esta puesta en escena se expresan con claridad. La posición y expresión facial del hombre arrodillado, que se entrega sufriente a la acción del dentista, refuerza su rol de paciente. El texto (de la fotografía y pie de foto) incorpora un elemento muy importante de la cultura occidental, la ciencia médica, en la presentación de la cultura mapuche, acercándola a la sociedad chilena. El no 19 impreso en blanco permite al lector asociar esta imagen con una cantidad de, al menos, otras 18 fotografías. Es decir, ésta sería parte de una colección sobre los "indios araucanos" (Azócar, 2005). Por último, el texto impreso en la parte inferior refuerza esta idea, pues es lógico interpretar que éste, escrito sobre el cartón y no sobre la fotografía, es común a las otras 18.

\section{DISCUSIÓN}

Plath, en relación al arsenal terapéutico dental utilizado por el pueblo mapuche, agrega que se disponían de variadas herramientas, entre ellas la Caraña o goma caraña, el clavo de olor, la raíz de Coro-Coro en infusión, la raíz de Pelitre y las raíces de Dichillo, que se masticaban para el tratamiento de las odontalgias. Por su parte, el Tomillo y el Orégano, a manera de esencia, eran utilizados para obtener el mismo beneficio. Los polvos del hollejo interior del huevo disminuían los "dolores de muelas". En el caso de los dientes cariados, eran muy utilizadas las lombrices muertas como tratamiento de las dolencias.

Entre sus recetas, figuraban las hojas de Palqui envueltas con granos de sal, las cuales se amarraban y se ponían al rescoldo, y luego, estando ya calientes, se colocaban dentro de la boca para el "dolor de mue- 
las”. El Romero en infusión se dejaba enfriar y se le ponía un poco de sal, también para aliviar el dolor. Por otro lado, al ser cocido con vinagre, adquiría nuevas propiedades, tales como, "reafirmar los dientes y muelas", fortificar las encías y aliviar el malestar de la boca, al ser usado caliente a manera de enjuague. En referencia a los enjuagues, se indicaban de aguardiente con orégano cocido, o de cebolla remojada con vinagre y sal, cuya indicación era "refregar sobre los dientes que duelan". Para la preparación de los Polvos de Cantárida, se recogían por la mañana, antes de salir el sol, 5 coleópteros, 3 dientes de ajo y un poco de triaca. Estos ingredientes se machacaban y se depositaban en un sutil pañito de lino, para luego colocarlo sobre la parte dolorida de la cara. Se dejaba esta cataplasma hasta que en la piel se hacían ampollas, momento en el cual se desvanecía el dolor.
La farmacoterapia para las odontalgias incluía el excreto de animales entre sus drogas, tales como el excremento blanco del perro, del ratón y del cerdo. Podemos apreciar, por lo tanto, que el pueblo mapuche disponía tanto de conceptos como de un sistema médico- religioso capaz de abordar acciones de carácter odontológico acorde a sus necesidades cotidianas (Plath).

\section{AGRADECIMIENTOS}

A la Facultad de Educación, Ciencias Sociales y Humanidades de la Universidad de La Frontera que contribuyó con sus observaciones a potenciar los contenidos y a mejorar la discusión de las ideas expresadas en este artículo.

AZÓCAR, A.; CANTÍN, M.; SILVA, M. H.; FLORES, L. T.; OTTONE, N. E. \& FUENTES, R. Iconic and iconographic analysis of a Mapuche dental procedure photographed by Gustavo Milet. Int. J. Odontostomat., 9(1):97-100, 2015.

ABSTRACT: The vital relationship of the Mapuche with the land, not only covers the area of material subsistence, but also involves a spiritual expression. The present study gives a subtle look at the complex medical/religious systems of the Mapuche people, their concepts of health, habits and actions to solve their daily medical-dental needs, which are revealed through a complete Iconic and iconographic analysis of a photograph by Gustavo Milet.

KEY WORDS: tooth extraction, dentists, Mapuche, photography.

\section{REFERENCIAS BIBLIOGRÁFICAS}

Azócar, A. Fotografía Proindigenista. El discurso de Gustavo Milet sobre los Mapuches. Temuco, Ediciones Universidad de la Frontera, 2005.

Instituto Nacional de Estadísticas. Estadísticas Sociales de los pueblos indígenas en Chile Censo 2002. 2005. Disponible en: http://www.ine.cl/canales/chile_estadistico/ estadisticas_sociales_culturales/etnias/pdf/ estadisticas_indigenas_2002_11_09_09.pdf.

Memoria Chilena. El pueblo Mapuche. Los primeros estudios (1882-1940). 2004. Disponible en: http:// www.memoriachilena.cl/602/w3-article-781.html.

Metz, C. Análisis de las Imágenes. Barcelona, Ediciones Buenos Aires, 1970.

Plath, O. Folklore Médico Chileno. Santiago, Editorial Nascimiento, 1981.

Zapater, H. Aborígenes Chilenos a través de Cronistas y Viajeros. $2^{\mathrm{a}}$ ed. Santiago, Editorial Andrés Bello, 1978.
Zúñiga Rocha, S. Algunos aspectos de las costumbres y reseña del cuidado del niño entre los antiguos araucanos. Ars Médica, 4:141-50, 2001.

Dirección de Correspondencia:

Ramón Fuentes

Departamento de Odontología Integral Adultos

Facultad de Odontología

Universidad de La Frontera

Av. Francisco Salazar 01145, Temuco

CHILE

Email: ramon.fuentes@ufrontera.cl

Recibido: 26-05-2014

Aceptado: 04-01-2015 